\title{
Hypolipidemic Effect of Rice Fermented With Monascus Ruber CCT 1236 in Rabbits
}

\author{
Cristiane S Fonseca1, Larissa F Brito ${ }^{1 *}$, Fabiano PPM1', Tânia T Oliveira², Sérgio LPM² and Jose H Queiroz \\ ${ }^{1}$ Department of Biochemistry and Molecular Biology, Federal University of Vicosa, Vicosa, 36570-000, Brazil \\ ${ }^{2}$ Department of General Biology, Federal University of Vicosa, 36570-000 Brazil
}

\begin{abstract}
The objective of the present work was to evaluate the effects of rice fermented with Monascus ruber in the concentrations of rabbit serum lipids and the possible protective effects of fermented rice in injuries caused by hyperlipidemy. Blood samples were collected at the beginning of the experiment and during the interval of fifteen and thirty days to determine the levels of serum lipids. The fermented rice was effective in increasing the highdensity lipoprotein cholesterol (HDL-C) and reducing total cholesterol (TC), triglyceride (TG), low-density lipoprotein cholesterol (LDL-c) and very low-density lipoprotein cholesterol (VLDL-c). These effects were more significant when the diet containing $10 \%$ of fermented rice was used. It was found that the addition of fermented rice in the diets of the animals did not change the morphology of cells of the heart and prevented the formation of injuries resulting from hyperlipidemy.
\end{abstract}

Keywords: Fermented rice; Cholesterol; Monascus ruber; Hyperlipidemy

\section{Introduction}

Since the decade of 60 , cardio vascular diseases are gradually increasing in the world, and the dyslipidemies are regarded as one of the determining factors to the development of these diseases, especially atherosclerosis. The elevation of serum triglycerides (TG), total cholesterol (TC) and low-density lipoprotein cholesterol (LDL-c), associated with a reduction of higher-density lipoprotein cholesterol (HDL-c) increases the likelihood of developing cardiovascular diseases [1]. It is essential to change the diet for the treatment of hypercholesterolemia. Epidemiological studies have provided evidence on the importance of diet as a risk factor for cardiovascular diseases, diabetes and cancers. Several foods and nutrients have been linked to the occurrence and to the prevention of chronic diseases in different populations [2,3]. The rice fermented with Monascus purpureus helped in the reduction of serum TC, LDL-c and TG, as well as increased HDL-c in animals and humans [4]. The reduction of serum lipids levels occurred by inhibition of HMG-CoA reductase, the key cholesterol biosynthesis enzyme [5,6]. Moreover, the rice fermented with Monascus purpureus contains fibers, magnesium, some B Vitamins and unsaturated fatty acids as oleic, linoleic and linolenic acids, which aid in the reduction of serum lipids [4]. A study of composition of rice fermented with Monascus purpureus showed the presence of $73.4 \%$ carbohydrates, $0.8 \%$ fibers, $14.7 \%$ proteins, $6.0 \%$ moisture, $0.3 \%$ pigments, $2.45 \%$ ash, $0.4 \%$ phosphorus, $0.02 \%$ organic phosphorus, $0.4 \%$ monacolins, $2.8 \%$ fatty acids, $0.03 \%$ Vitamin $\mathrm{C}$ and Vitamin $\mathrm{A}<70 \mathrm{IU} / 100 \mathrm{~g}$. The white rice does not have Vitamins $\mathrm{A}$ and $\mathrm{C}$ and monacolins. Besides this, the amount of other nutrients was lower than that present in the fermented rice $[7,8]$. The most used synthetic medicines for the treatment of hyperlipidemy contain statins, fib rates and inhibitors of HMG-Co A reductase as active principle. The inhibitors drugs of HMG-Co A reductase effectively reduce the mortality and coronary events, being highlighted in the prevention and control of dislipidemy [9]. Besides these, plant extracts and metabolites of fungi inhibit HMG-CoA reductase [10]. In this sense, fermented products with Monascus ruber could assist in the treatment of hyperlipidemies. This study aimed to evaluate the effects of rice fermented with fungus Monascus ruber in the concentrations of serum lipids and in histopathology of the heart and aorta of rabbits.

\section{Materials and Methods}

\section{Chemicals}

Agar dextrose potato was purchased from Biobrás ${ }^{\circledR}$ (Belo Horizonte, Minas Gerais, Brazil), commercial chow from SOCIL (São Paulo, Brazil), cholesterol from VETEC (Rio de Janeiro, Brazil) and enzymatic kits from BioMérieux (Brazil).

\section{Microorganism and strain conservation}

The filamentous fungus Monascus rubber CCT 1236 was acquired from the Tropical Research Foundation and Andrew Tosello Technology (Campinas, Sao Paulo, Brazil). The conservation of the Strain was done in inclined PDA mean. After the transplant, the strain was wrapped in incubator at $28^{\circ} \mathrm{C}$ for 7 days and stored at $5^{\circ} \mathrm{C}$ in refrigerator.

\section{Production of fermented rice}

The brand of rice Candy, parboiled, long thin, type 1 was used. Fifty grams of this rice were homogenized with $60 \mathrm{ml}$ of solution containing $0.05 \% \mathrm{MgSO}_{4}, 0.05 \% \mathrm{KH}_{2} \mathrm{PO}_{4}$ and $0.5 \% \mathrm{NH}_{4} \mathrm{Cl}$, to enrich the environment and raise the moisture level. The Erlenmeyer bottle were sealed and left to rest for 15 min to balance the humidity inside the grains. After that, Erlenmeyer bottle were sterilized in the autoclave for $20 \mathrm{~min}$ at $121^{\circ} \mathrm{C}$. After refrigerated, suspensions containing spores kept in PDA were inoculated in the sterilized culture medium. Then, the bottles were placed in greenhouse incubator at $28^{\circ} \mathrm{C}$ for thirteen days. The fermented rice was dry in oven with forced air circulation for $24 \mathrm{~h}$ at $65^{\circ} \mathrm{C}$. After cooling, the rice was ground in a multiprocessor and the flour was used in the experimental diets.

*Corresponding author: Larissa F Brito, Department of Biochemistry and Molecular Biology, Federal University of Vicosa, 36570-000, Brazil, Tel: 3194195158; E-mail: larissafroede@yahoo.com.br

Received June 28, 2014; Accepted September 05, 2014; Published September 08, 2014

Citation: Fonseca CS, Brito LF, Fabiano PPM, Oliveira TT, Sérgio LPM, et al. (2014) Hypolipidemic Effect of Rice Fermented With Monascus Ruber CCT 1236 in Rabbits. Nat Prod Chem Res 2: 144. doi:10.4172/2329-6836.1000144

Copyright: (c) 2014 Fonseca CS, et al. This is an open-access article distributed under the terms of the Creative Commons Attribution License, which permits unrestricted use, distribution, and reproduction in any medium, provided the original author and source are credited. 


\section{Biological trial}

Thirty-six New Zealand male rabbits with fifty days old and average weight of $1,700 \mathrm{~g}$ were used. The rabbits received $100 \mathrm{~g} /$ day of commercial feed (basal diet) and water ad libitum during the acclimation period of seven days. The animals were randomly divided into six groups, containing six rabbits each (Table 1). During the experimental period, the animals were kept in individual cages with natural ventilation. After that time, the experiment began with the addition of cholesterol to the diets for the induction of hyperlipidemy, except for the control group (G1). The fermented rice and feed were ground before the preparation of the experimental diets. The care and procedures adopted for the present investigation were in accordance with the Ethics Norms of Lab oratory Animal Research as determined by Brazilian College of Animal Experimentation [11] (Table 1).

\section{Biochemical analysis}

The doses of total cholesterol (TC), triglycerides (TG), high-density lipoprotein cholesterol (HDL-c), low-density lipoprotein cholesterol (LDL-c) and very low-density lipoprotein cholesterol (VLDL-c) were performed at the end of the period of adaptation of animals (zero time) and after fifteen and thirty days of trial. The collect of blood was performed in animals that were fasting for twelve hours through the retro-orbital venous plexus using capillary tube. Samples of blood of

\section{Animal groups Experimental diets}

\section{G1 Chow}

G2 Chow $+1 \%$ cholesterol (w/w)

G3 Chow $+1 \%$ cholesterol $(w / w)+10 \%$ unfermented rice $(w / w)$

G4 Chow $+1 \%$ cholesterol $(w / w)+1 \%$ fermented rice $(w / w)$

G5 Chow $+1 \%$ cholesterol $(w / w)+5 \%$ fermented rice (w/w)

G6 Chow $+1 \%$ cholesterol $(w / w)+10 \%$ fermented rice $(w / w)$

Table 1: Composition of the experimental diets. the animals were centrifuged at 7,100xg for 15 min to get the serum. The serological dosages were developed in the multi-parametric of biochemistry equipment of dosages (Alizé), using specific kits.

\section{Morphological analysis}

Fragments of cardiac tissue and from the initial aorta's region to the aortic arch of the rabbits were collected to assess the deposition of cholesterol and triglycerides. Those segments were no more than $3 \mathrm{~mm}$ in thickness and were fixed in sodium phosphate buffer 0.1 $\mathrm{M}, \mathrm{pH} 7.4$, containing $4 \%$ glutaraldehyde $(\mathrm{v} / \mathrm{v})$ for $4 \mathrm{~h}$ at $4^{\circ} \mathrm{C}$. Then, these fragments were transferred to the same buffer and stored under refrigeration until processing. This material was dehydrated in ethanol growing series, cleared in xilol and included in paraffin. The fragments were cut in rotary microtome with steel razor in thickness of $4 \mathrm{~m}$ and set in layers of glass. The cuts were stained with hematoxylineosin and analysed in light microscopy.

\section{Statistical analysis}

The results were expressed as mean \pm standard deviation. The means of the control groups G1 and G2 were compared by test F. The comparison of the other experimental groups with control groups was performed by the test Dunnett. The average of the results obtained from the experimental groups was compared each other using the Tuckey test at $5 \%$ level of probability.

\section{Results}

\section{Effects of fermented rice in the levels of total cholesterol and triglycerides}

In the beginning of the experiment, the basal diet-fed animals (G1) and basal diet-cholesterol-fed animals (G2) showed differences in the levels of total cholesterol $(p<0.05)$ (Table 2), while those that received

\begin{tabular}{|c|c|c|c|c|c|}
\hline Treatment time (days) & Group $^{f}$ & Total cholesterol $(\mathrm{mg} / \mathrm{dL})^{\mathrm{g}}$ & Variation (\%) & Triglycerides $(\mathrm{mg} / \mathrm{dL})^{\mathrm{g}}$ & Variation (\%) \\
\hline \multirow{6}{*}{0} & G1 & $83.78 \pm 5.46^{\mathrm{B}}$ & - & $77.54 \pm 8.41^{\mathrm{A}}$ & - \\
\hline & G2 & $96.17 \pm 3.00^{\mathrm{A}}$ & - & $89.95 \pm 5.86^{A}$ & - \\
\hline & G3 & $148.83 \pm 29.48^{a}$ & $+54.75^{\star *}$ & $91.47 \pm 11.90^{\mathrm{a}}$ & +1.6 \\
\hline & G4 & $96.43 \pm 12.73^{a}$ & +0.27 & $79.81 \pm 8.41^{\mathrm{a}}$ & -11.2 \\
\hline & G5 & $94.43 \pm 5.74^{a}$ & -1.81 & $90.53 \pm 5.19^{a}$ & +0.6 \\
\hline & G6 & $110.23 \pm 8.37^{a}$ & +14.62 & $90.28 \pm 10.11^{\mathrm{a}}$ & +0.3 \\
\hline \multirow{6}{*}{15} & G1 & $93.73 \pm 8.55^{\mathrm{B}}$ & - & $94.74 \pm 8.87^{\mathrm{B}}$ & - \\
\hline & G2 & $3,401.00 \pm 141.31^{\mathrm{A}}$ & - & $149.03 \pm 26.57^{A}$ & - \\
\hline & G3 & $3,264.17 \pm 258.63^{a}$ & -4.02 & $119.75 \pm 26.24^{\mathrm{a}}$ & -19.6 \\
\hline & G4 & $2,999.17 \pm 274.15^{a}$ & -11.81 & $91.78 \pm 7.33^{a}$ & $-32.4^{* *}$ \\
\hline & G5 & $2,879.00 \pm 165.00^{\mathrm{a}}$ & $-15.35^{* *}$ & $101.26 \pm 12.64^{\mathrm{a}}$ & $-32.0^{* *}$ \\
\hline & G6 & $2,665.00 \pm 99.64^{a}$ & $-21.64^{* *}$ & $87.81 \pm 12.33^{\mathrm{a}}$ & $-41.0^{* *}$ \\
\hline \multirow{6}{*}{30} & G1 & $92.31 \pm 4.26^{\mathrm{B}}$ & - & $105.75 \pm 9.30^{\mathrm{B}}$ & - \\
\hline & G2 & $4,487.00 \pm 183.31^{\mathrm{A}}$ & - & $230.14 \pm 36.82^{\mathrm{A}}$ & - \\
\hline & G3 & $4,119.50 \pm 266.59^{a}$ & -8.19 & $218.63 \pm 63.03^{a}$ & -5.0 \\
\hline & G4 & $3,623.33 \pm 344.86^{\mathrm{ab}}$ & $-19.25^{* *}$ & $150.40 \pm 23.40^{\mathrm{ab}}$ & $-34.65^{* *}$ \\
\hline & G5 & $3,098.00 \pm 128.01^{\mathrm{bc}}$ & $-30.96^{* *}$ & $137.84 \pm 33.41^{\mathrm{ab}}$ & $-40.11^{* *}$ \\
\hline & G6 & $2,820.50 \pm 92.26^{c}$ & $-37.14^{* *}$ & $111.75 \pm 8.46^{\mathrm{b}}$ & $-51.44^{* *}$ \\
\hline
\end{tabular}

${ }^{\mathrm{f}}$ Basal diet-fed group (G1), basal diet-cholesterol-fed group (G2), basal diet-cholesterol-unfermented rice-fed group (G3), basal diet-cholesterol-1\% fermented rice-fed group (G4), basal diet-cholesterol-5\% fermented rice-fed group (G5), basal diet-cholesterol-10\% fermented rice-fed group (G6)

${ }^{g}$ Values are averages \pm standard deviation. Means followed by the same capital or lowercase letter within a column are not significantly different by Tuckey test ( $\left.p<0.05\right)$. **Significantly differ of the control group $\mathrm{G} 2$ by Dunnet test at $5 \%$ significance level

Table 2: Effects of unfermented and fermented rice in the total cholesterol (TC) and triglycerides (TG) levels of $r$ abbits. 
unfermented (G3) and fermented rice (G4, G5 and G6) presented no significant difference. It was also observed that the group G3 showed significant difference in relation to the control group G2. On the contrary, the triglycerides levels did not differ significantly between groups G1 and G2 neither did between the groups G3 and G2 in the beginning of the experiment.

Total cholesterol and triglycerides levels of the basal dietcholesterol-fed rabbits (control group G2) were significantly higher $(p<0.05)$ than those of the basal diet-fed rabbits group (G1) after 15 days of experiment (Table 2), which demonstrates the efficiency of cholesterol $1 \%(\mathrm{w} / \mathrm{w})$ to induce hypercholesterolemy. Cholesterol level variation of $5 \%$ fermented rice-fed rabbits (group G5) and $10 \%$ fermented rice-fed rabbits (group G6) were lower $(p<0.05)$ comparing to basal diet-cholesterol-fed rabbits (control group G2) after 15 days of trial. This can be attributed to the greater quantity of fermented rice present in the diet of those groups.

That effect was more pronounced at the end of the experiment, when the $1 \%$ fermented rice-fed rabbits (group G4) also had lower variation in cholesterol $(p<0.05)$ than those fed the control group G2. Furthermore, cholesterol level variation in the unfermented rice-fed rabbits (group G3) did not differ ( $p>0.05$ ) from those in group G2, even at the end of the experiment. It was also seen that the serum levels of total cholesterol of animals treated with $5 \%$ and $10 \%$ of fermented rice (groups G5 and G6, respectively) were lower $(p<0.05)$ than those observed for the animals submitted to unfermented rice (group G3) after thirty days.

The groups treated with fermented rice (groups G4, G5 and G6) had serum cholesterol levels significantly lower than those of the control group G2 (Table 2) after thirty days of trial. The 10\% fermented rice diet reduced the cholesterol level in approximately $37 \%$, demonstrating the efficacy of this pro duct in the reduction of total cholesterol. Animals sub mitted to diets containing fermented rice had lower variation in triglycerides $(p<0.05)$ than those of control group G2 after fifteen days of treatment. This effect was higher with $10 \%$ fermented rice which was the only one able to reduce significantly the triglycerides levels comparing to the diet containing unfermented rice (group G3) (Table $2)$. The last group did not differ $(p>0.05)$ from group G2.

\section{Effects of fermented rice in the levels of LDL-c, HDL-c and VLDL-c}

The differences observed between the levels of LDL-c and HDL-c of the control groups G1 and G2, after 15 days of trial, confirmed the efficiency of cholesterol to increase the levels of those lipoprotein fractions (Table 3).

Animals submitted to diets containing $5 \%$ to $10 \%$ of fermented rice (groups G5 and G6, respectively) showed variations in the LDL-c levels significantly lower than those fed chow and cholesterol (group G2) (Table 3). This effect was more pronounced at the end of the experiment, when the diet containing $1 \%$ of fermented rice (group G4) also promoted lower variation in the levels of LDL-c $(p<0.05)$ than that containing only chow and cholesterol.

The rabbits submitted to diets containing the fermented rice had LDL-c levels lower $(p<0.05)$ than those not fed fermented rice at the end of the experiment (Table 3). The fermented rice-fed animals (groups G4, G5 and G6) showed no significant increase ( $p>0.05)$ in the levels of HDL-c in relation to those fed only basal diet and cholesterol (group

\begin{tabular}{|c|c|c|c|c|c|c|c|}
\hline Treatment time (days) & Group & LDL-C (mg/dL) g & Variation (\%) & HDL-c (mg/dL) & Variation (\%) & VLDL-c (mg/dL) & Variation (\%) \\
\hline \multirow{6}{*}{0} & G1 & $45.54 \pm 2.55^{\mathrm{A}}$ & - & $22.73 \pm 3.17^{\mathrm{B}}$ & - & $15.51 \pm 1.68^{\mathrm{B}}$ & - \\
\hline & G2 & $43.14 \pm 1.97^{A}$ & - & $36.74 \pm 5.05^{A}$ & - & $28.99 \pm 5.17^{A}$ & - \\
\hline & G3 & $72.88 \pm 7.17^{a}$ & $+68.94^{* *}$ & $36.46 \pm 3.11^{\mathrm{ab}}$ & -0.76 & $18.29 \pm 2.38^{a}$ & $-36.90^{* *}$ \\
\hline & G4 & $18.12 \pm 3.29^{c}$ & $-57.60^{* *}$ & $25.18 \pm 1.92^{b}$ & $-31.46^{\star *}$ & $15.96 \pm 1.68^{c}$ & $-45.05^{\star *}$ \\
\hline & G5 & $48.87 \pm 7.60^{b}$ & +13.28 & $32.26 \pm 3.53^{\mathrm{ab}}$ & -12.19 & $18.11 \pm 1.04^{b}$ & $-37.53^{\star *}$ \\
\hline & G6 & $41.12 \pm 8.21^{\mathrm{b}}$ & -4.68 & $40.65 \pm 4.04^{\mathrm{a}}$ & +10.64 & $18.05 \pm 2.02^{\mathrm{b}}$ & $-37.74^{* *}$ \\
\hline \multirow{6}{*}{15} & G1 & $45.77 \pm 5.53^{\mathrm{B}}$ & - & $33.00 \pm 9.44^{\mathrm{B}}$ & & $25.39 \pm 4.36^{A}$ & - \\
\hline & G2 & $2,838.8 \pm 81.18^{\mathrm{A}}$ & - & $510.66 \pm 73.61^{\mathrm{A}}$ & & $24.54 \pm 4.20^{A}$ & - \\
\hline & G3 & $2,610.31 \pm 257.31^{a}$ & -8.05 & $629.90 \pm 7.19^{a}$ & \multirow{2}{*}{$-23.35^{\star *}$} & $23.86 \pm 5.26^{a}$ & -2.77 \\
\hline & G4 & $2,666.83 \pm 217.07^{a}$ & -5.06 & $565.72 \pm 56.78^{\mathrm{a}}$ & & $12.36 \pm 1.46^{a}$ & $-51.32^{* *}$ \\
\hline & G5 & $2,367.27 \pm 120.89^{a}$ & $-16.61^{* *}$ & $488.56 \pm 53.18^{a}$ & ) & $17.5 \pm 2.44^{\mathrm{a}}$ & -30.52 \\
\hline & G6 & $2,171.64 \pm 114.76^{a}$ & $-23.50^{* *}$ & $555.94 \pm 22.14^{\mathrm{a}}$ & +8.87 & $17.92 \pm 4.23^{\mathrm{a}}$ & -29.42 \\
\hline \multirow{6}{*}{30} & G1 & $37.55 \pm 4.07^{\mathrm{B}}$ & - & $45.33 \pm 13.45^{B}$ & - & $21.15 \pm 1.86^{\mathrm{B}}$ & - \\
\hline & G2 & $3,498.38 \pm 143.74^{A}$ & - & $714.57 \pm 148.79^{A}$ & - & $46.03 \pm 7.36^{A}$ & - \\
\hline & G3 & $3,429.28 \pm 331.84^{a}$ & -1.96 & $720.15 \pm 115.38^{a}$ & +0.78 & $43.73 \pm 12.60^{\mathrm{a}}$ & -4.99 \\
\hline & G4 & $2,645.55 \pm 340.02^{b}$ & $-24.38^{* *}$ & $810.89 \pm 110.59^{a}$ & +13.48 & $24.35 \pm 7.42^{\mathrm{ab}}$ & $-47.10^{* *}$ \\
\hline & G5 & $2,178.46 \pm 114.81^{b}$ & $-37.73^{* *}$ & $895.85 \pm 23.37^{a b}$ & +25.37 & $24.62 \pm 2.87^{\mathrm{ab}}$ & $-46.51^{* *}$ \\
\hline & G6 & $2,270.06 \pm 78.66^{b}$ & $-35.11^{* *}$ & $956.45 \pm 122.31^{b}$ & $+33.85^{\star *}$ & $22.35 \pm 1.69^{\mathrm{ab}}$ & $-51.44^{* *}$ \\
\hline
\end{tabular}

fBasal diet-fed group (G1), basal diet-cholesterol-fed group (G2), basal diet-cholesterol-in fermented rice-fed group (G3), basal diet-cholesterol-1\% fermented rice-fed group (G4), basal diet-cholesterol-5\% fermented rice-fed group (G5), basal diet-cholesterol-10\% fermented rice-fed group (G6).

gValues are averages \pm standard deviation. Means followed by the same capital or lowercase letter within a column are not significantly different by Tuckey test ( $<<0.05)$. ${ }^{* *}$ Significantly differ of the control group $\mathrm{G} 2$ by Dunnet test at $5 \%$ significance level

Table 3: Effects of unfermented and fermented rice in the low-density lipoprotein cholesterol (LDL-c), high-density lipoprotein cholesterol (HDL-c) and very low-density lipoprotein cholesterol (VLDL-c) levels of rabbits. 
G2) after 15 days of experiment (Table 3). Only after the $30^{\text {th }}$ day, the rabbits submitted to the diet containing $10 \%$ of fermented rice (group G6) showed significant increase in the levels of HDL-c in comparison to the animals of the group G2.

The $1 \%$ fermented rice-fed rabbits (group G4) showed less variation in the level of VLDL-c in relation to the basal diet-cholesterol-fed rabbits (group G2) after 15 days of trial (Table 3). This effect was observed for the other groups of animals fed diet containing fermented rice (groups G5 and G6) at the end of the experiment. The variation of LDL-c, HDL-c and VLDL-c observed for the unfermented rice-fed rabbits (group G3) differed no significantly $(p>0.05)$ of that observed for the control group G2 at the end of trial, whereas contrary effects were demonstrated for rabbits fed fermented rice.

\section{Effects of rice fermented with Monascus on the prevention of injuries in the aorta of rabbits}

Animals submitted to diet containing 10\% fermented rice (group G6) had less intense tissue injury compared to those of the group that received only basal diet and cholesterol (group G2), suggesting a tendency to prevention and / or reduction of tissue damage in animals that consumed the fermented rice (Figures $1 \mathrm{~A}$ and $1 \mathrm{~B}$ ).

Comparing pieces of aortic tissue from animals fed basal diet and cholesterol (group G2), with those fed diet, cholesterol and fermented rice (group G6) (Figures $2 \mathrm{~A}$ and $2 \mathrm{~B}$ ), it was observed that animals fed fermented rice had no injuries as extensive as those of the groups of

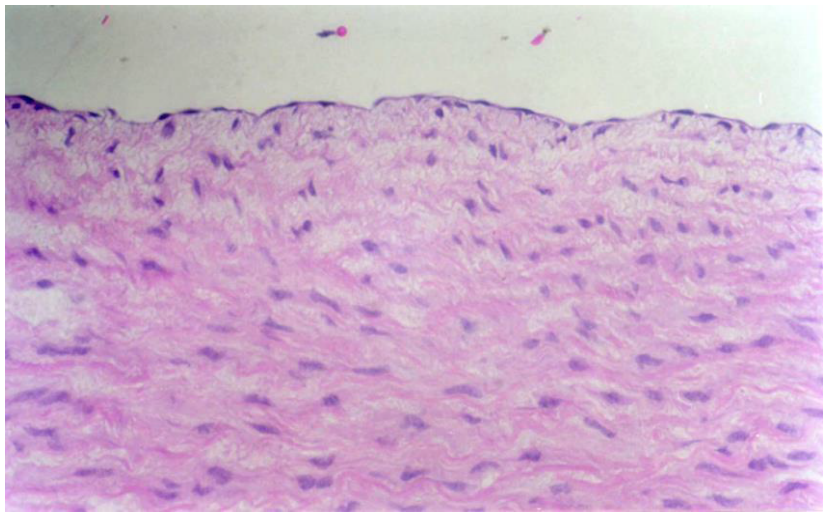

Figure 1A: Tissue damage in animals that consumed the fermented rice.

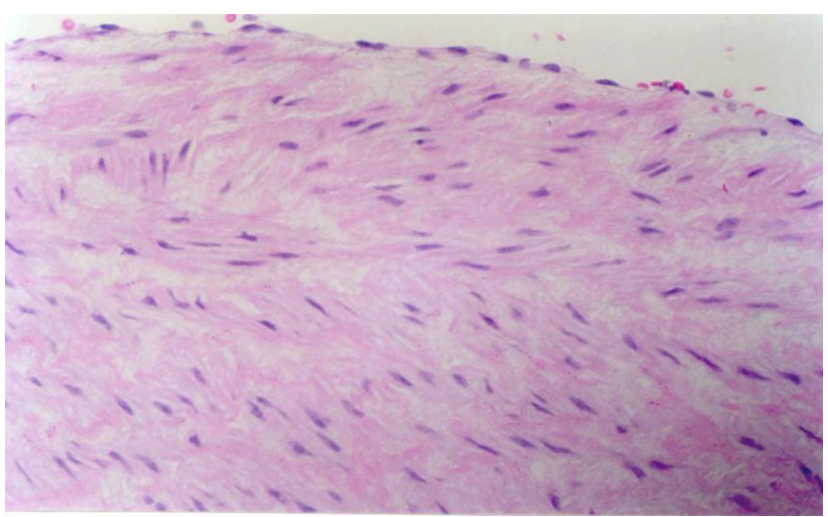

Figure 1B: Tissue damage in animals that received only basal diet and cholesterol.
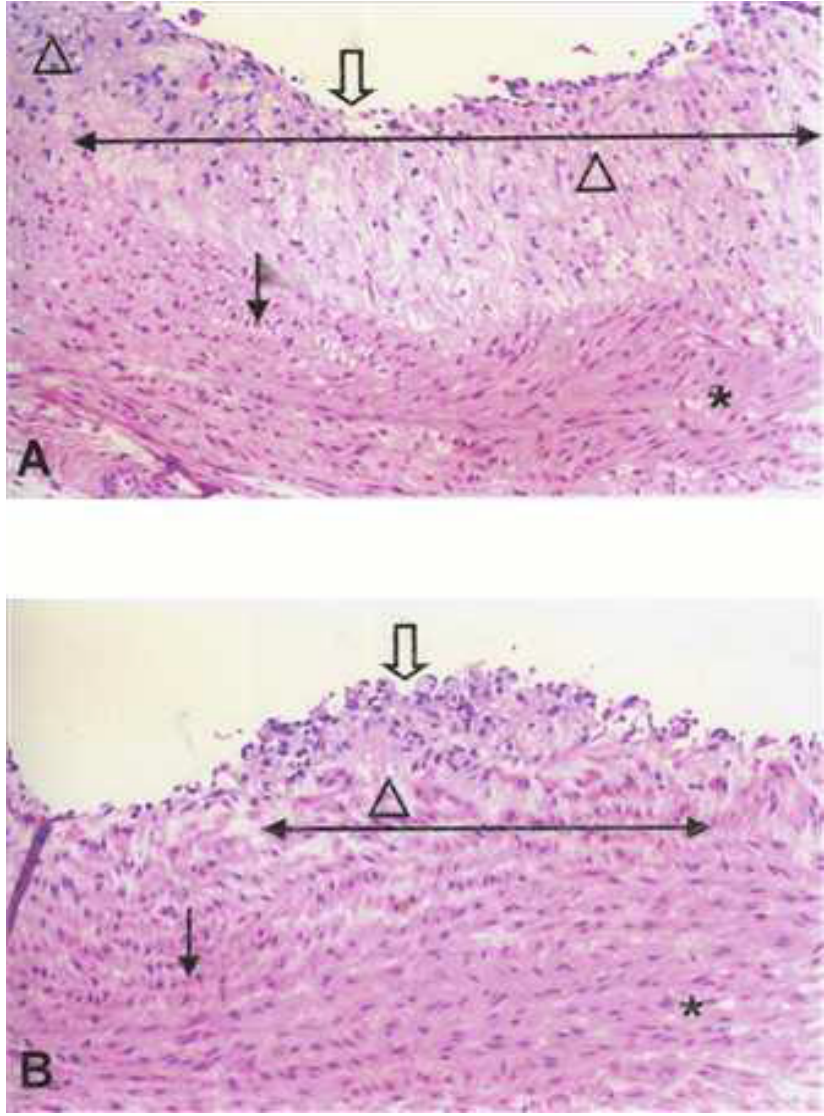

Figure 2A and 2B: Comparing pieces of aortic tissue from animals fed basal diet and cholesterol (group G2), with those fed diet, cholesterol and fermented rice (group G6).

animals that did not receive it. In this way, fermented rice prevented the emergence of foam cells in animals.

\section{Discussion}

The efficacy of cholesterol to induce hypercholesterolemy in the present study has been reported, demonstrating that fermented rice was able to reduce total cholesterol [12]. Other studies have been reported the effect of rice fermented with Monascus fungus in the cholesterol levels. The use of rice fermented with Monascus purpureus reduced between $24 \%$ and $59 \%$ the levels of total cholesterol in hyperlipidemic rabbits depending on the amount of rice used and on the inducing source of hyperlipidemy [13]. According to these authors, adding up 8 mg of pure mevinolin by $\mathrm{kg}$ of bod y weight the level of total cholesterol was reduced 52\%. The consumption of rice fermented with Monascus purpureus in hyperlipidemic humans promoted the reduction of the level of total cholesterol between $17 \%$ and $22.7 \%$ [5,14]. In the present study, a reduction of approximately $37 \%$ in the level of total cholesterol for the group receiving 10\% fermented rice (group G6) was obtained.

Diet containing rice fermented with Monascus in the concentration of $2 \%$ decreased significantly the serum triglycerides concentrations in rats [15]. In the present work, that effect occurred in the concentration of $1 \%, 5 \%$ and $10 \%$ of fermented rice. Reduction of approximately $12 \%$ of triglycerides was reported when $2.4 \mathrm{~g}$ of rice fermented with Monascus purpureus were added to the diet of hyperlipidemic adults [14]. Even more reduction in the level of triglycerides (34\%) has been observed in hyperlipidemic adults treated with a diet containing rice fermented 
by the same kind of fungus [5]. In this study, rabbits treated with diet containing $10 \%$ fermented rice showed reduction of approximately $51 \%$ in the triglycerides level after thirty days of experiment. Using 4 $0 \mathrm{mg}, 80 \mathrm{mg}$ and $100 \mathrm{mg}$ of dye stuff Monascus, it was found that the higher dosage increased the triglycerides to $147 \mathrm{mg} / \mathrm{dl}$. However, it was estimated that $35.3 \mathrm{mg}$ of dye stuff significantly reduced the levels of triglycerides to $97.9 \mathrm{mg} / \mathrm{dl}$ [16]. The effectiveness of fermented rice to reduce the levels of LDL-c has been reported in some studies.

The inclusion of $0.8 \mathrm{~g} / \mathrm{kg}$ body weight/day of rice fermented with Monascus purpureus in experimental diet reduced the LDL-c levels of rabbits in $44 \%$ [13]. The use of $2.4 \mathrm{~g}$ of rice fermented with Monascus purpureus reduced the serum LDL-c levels of hyperlidemic humans in approximately $23 \%$ [14], while a reduction of $34 \%$ in the levels of LDL-c was observed by Wang et al. [5]. The use of Anka in the concentration of $2 \%$ significantly reduced the LDL-c levels in hypertriglyceridemic rats $12 \%$ approximately [15]. Agreeing with the afore mentioned works, the diet on tanning fermented rice used in the present work promoted a reduction of approximately $37 \%$ in the LDL-c levels comparing to the diet having only basal diet and cholesterol.

The use of dye produced by Monascus caused significant increase in the HDL-c in rabbits depending on the time of experiment [16]. However, it was observed that the use of $2.4 \mathrm{~g}$ of rice fermented with Monascus purpureus in human diet did not promote significant increase in the levels of HDL-c [14]. Agreeing with the former study, the diet containing $10 \%$ fermented rice has been able to increase HDL-c at the end of experiment.

The experimental diet containing $2 \%$ of rice fermented with Monascus significantly reduced VLDL-c in rats [15]. In this study, even the diet containing $1 \%$ rice fermented with Monascus ruber has been able to reduce VLDL-c after 30 days of trial. The consumption of fermented rice with Monascus purpureus reduced the formation of atherosclerotic plaques in hyperlipidemic rabbits [13], similar to the results obtained in this study.

The use of synthetic drugs has been effective in the treatment of hyperlipidemy. The use of statins in hypercholesterolemic rabbits significantly reduced the occurrence of atherosclerosis, reversing endothelial dysfunction caused by hypercholesterolemy and reducing the number of foam cells observed in the thoracic aorta [9]. Those drugs cause similar effects to those found in this study using rice fermented with Monascus which is a food usually consumed in Asian countries [4].

Thus, our work has confirmed that rice fermented with Monascus ruber presents potential Cardio protective by increasing the levels of HDL-c and decreasing the levels of total cholesterol, triglycerides, VLDL-c and LDL-c. This effect was more pronounced when the diet containing $10 \%$ of fermented rice was administered to rabbits.

In addition, the fermented rice prevented the emergence of large tissue injuries, which was evidenced by the lack of change in morphology of the cells of the intimate tunica artery of animals treated with diet containing this fermented rice.

\section{References}

1. Grillo LP, Crispim SP, Siebert AN, Andrade ATW, Rossi A, et al. (2005) Lipid profile and obesity in low income school children. Rev Bras Epidemiol 8: 75-81.

2. Bertolino CN, Castro TG, Sartorelli DS, Ferreira SR, Cardoso MA (2006) Dietary trans fatty acid intake and serum lipid profile in Japanese-Brazilians in Bauru, São Paulo, Brazil. Cad Saude Publica 22: 357-364.

3. Lopes AC, Caiaffa WT, Sichieri R, Mingoti SA, Lima-Costa MF (2005) Nutrient consumption by adults and seniors in a population-based study: the Bambui Project. Cad Saude Publica 21: 1201-1209.

4. Erdogrul O, Azirak S (2005) A review on the red yeast rice (Monascus purpureus) Journal of Science and Engineering 8:10-15.

5. Wang J, Lu Z, Chi J, Wang W, Su M, et al. (1997) Multicenter clinical tria of the serum lipid-lowering effects of a Monascus purpureus (red yeast) rice preparation from traditional Chinese medicine. Current Therapeutic Research 58: $964-978$

6. Endo A, Hasumi K, Nakamura T, Kunishima M, Masuda M (1985) Dihydromonacolin $\mathrm{L}$ and monacolin $\mathrm{X}$, new metabolites which inhibit cholestero biosynthesis. J Antibiot (Tokyo) 38: 321-327.

7. Franco G (1999) Table of Food Chemical Composition, 7th ed, Atheneu, Rio de Janeiro.

8. Ma J, Li Y, Ye Q, Li J, Hua Y, et al. (2000) Constituents of red yeast rice, a traditional Chinese food and medicine. J Agric Food Chem 48: 5220-5225.

9. Jorge PAR, Almeida EA, Ozaki MR, Jorge M, Carneiro A (2005) Effects of atorvastatin, fluvastatin, pravastatin and simvastatin on endothelial function, lipid peroxidation and aortic atherosclerosis in hypercholesterolemic rabbits. Arq Bras Cardiol 84: 314-319.

10. Gonçalves MCR, Moura LSA, Rabelo LA, Filho JMB, Cruz HMM, et al. (2000) Natural products inhibitors of the enzyme HMG-CoA reductase. Brazilian Journal of Pharmacy 81: 63-71.

11. Brazilian College of Animal Experimentation - COBEA (1991) Ethical principles in animal experimentation. Brazilian College of Animal Experimentation, Brazil.

12. Grundy SM (1983) Absorption and metabolism of dietary cholesterol. Annu Rev Nutr 3: 71-96.

13. Li C, Zhu Y, Zhu JS, Chang J, Kritchevsky D (1998) Monascus purpureus -fermented rice (red yeast rice): a natural food product that lowers blood cholesterol in animal models of hypercholesterolemia. Nutrition Research 18: $71-81$.

14. Heber D, Yip I, Ashley JM, Elashoff DA, Elashoff RM, et al. (1999) Cholesterollowering effects of a proprietary Chinese red-yeast-rice dietary supplement. Am J Clin Nutr 69: 231-236.

15. Wang IK, Lin-Shiau SY, Chen PC, Lin JK (2000) Hypotriglyceridemic effect of Anka (a fermented rice product of monascus sp.) in rats. J Agric Food Chem 48: 3183-3189.

16. Oliveira TT, Nagen TJ, Lopes RM, Moraes GHK, Silva RR, et al. (2002) Monascus effects on blood constituents rabbits. Brazilian Journal of Clinical Analysis 34: 213-219. 